\title{
A large pseudoaneurysm of the left cardiac ventricle in a 57-year-old patient after urgent coronary artery bypass grafting and surgical mitral valve replacement due to acute myocardial infarction
}

\author{
Joanna Wieczorek, Katarzyna Mizia-Stec, Anna Rybicka-Musialik, Piotr Janusiewicz, Marcin Malinowski, \\ Marek A. Deja
}

Independent Public Clinical Hospital No. 7, Medical University of Silesia in Katowice, Prof. Leszek Giec Upper Silesian Medical Centre, Katowice, Poland

Kardiochirurgia i Torakochirurgia Polska 2014; 11 (4): 432-436

\begin{abstract}
We present a rare case of a left ventricular pseudoaneurysm in a patient after inferior wall myocardial infarction. The infarction was complicated with acute mitral insufficiency, pulmonary edema, and cardiogenic shock. Urgent surgical mitral valve replacement and coronary artery bypass grafting were performed. After several months, the patient was hospitalized again because of deterioration of exercise tolerance and symptoms of acute congestive heart failure. A large pseudoaneurysm of the left ventricle was recognized and successfully treated surgically.
\end{abstract}

Key words: left ventricular pseudoaneurysm, acute myocardial infarction.

\section{Case study}

The 57-year-old patient with multivessel coronary artery disease, hyperlipidemia treated with pharmacotherapy, paroxysmal atrial fibrillation, and stage 3 chronic kidney disease (CKD 3) was admitted due to increasing symptoms of chronic heart failure in NYHA (New York Heart Association) class III. The patient denied experiencing episodes of collapse, heart palpitations, or loss of consciousness. Seven months earlier, he had suffered an inferior wall myocardial infarction with ST-segment elevation and was treated with transcutaneous angioplasty of the right coronary artery with bare-metal stent (BMS) implantation. The infarction was complicated with acute mitral insufficiency, pulmonary edema, and cardiogenic shock. At the time, he was urgently treated with coronary artery bypass grafting (Ao-OM1, Ao-RCA) and was implanted with a mechanical valve (St. Jude 27) in the mitral position. Postoperatively, global

\section{Streszczenie}

W pracy zaprezentowano rzadki przypadek tętniaka rzekomego u pacjenta po zawale ściany dolnej mięśnia sercowego. Zawał powikłany był ostrą niedomykalnością zastawki mitralnej, obrzękiem płuc i wstrząsem kardiogennym. W trybie pilnym wykonano pomostowanie aortalno-wieńcowe oraz implantowano zastawkę mechaniczną w pozycję mitralną. W ciągu kilku następnych miesięcy u chorego zaobserwowano pogorszenie tolerancji wysiłku i zaostrzenie niewydolności serca. Podczas ponownej hospitalizacji u pacjenta rozpoznano ogromnego tętniaka rzekomego ściany dolnej, którego z dobrym efektem leczono chirurgicznie.

Stowa kluczowe: tętniak rzekomy, ostry zawał mięśnia sercowego.

left ventricular contractility impairments were observed with a reduction of ejection fraction to $40 \%$ and hypokinesia of the apex and inferior wall.

At admission, 12-lead electrocardiography revealed atrial fibrillation (ventricular action at approx. 86/min), intraventricular conduction impairments (QRS $130 \mathrm{~ms}$ ), pathological Q waves, and persistent ST-segment elevation in leads II, III, and aVF, elevated R waves in leads V1-V3, as well as diagonally downward ST-segment depressions and negative-positive T waves in leads V2-V4. Echocardiographic examination revealed the presence of a large aneurysm of the inferior cardiac wall (aneurysm entrance approx. $5 \mathrm{~cm}$, diameter approx. $5 \mathrm{~cm}$ ) (Fig. 1A), akinesia of the paraapical segment of the inferior wall with generalized hypokinesia of the remaining walls, and global left ventricular systolic function impairment with ejection fraction reduced to $30 \%$. The function of the mitral valve was normal;

Address for correspondence: Joanna Wieczorek, Independent Public Clinical Hospital No. 7, Medical University of Silesia in Katowice, Prof. Leszek Giec, Upper Silesian Medical Centre, Katowice, Poland, 45/47 Ziołowa St., 40-635 Katowice, phone: +48 504 243701 ,

e-mail: wie.joanna@gmail.com 


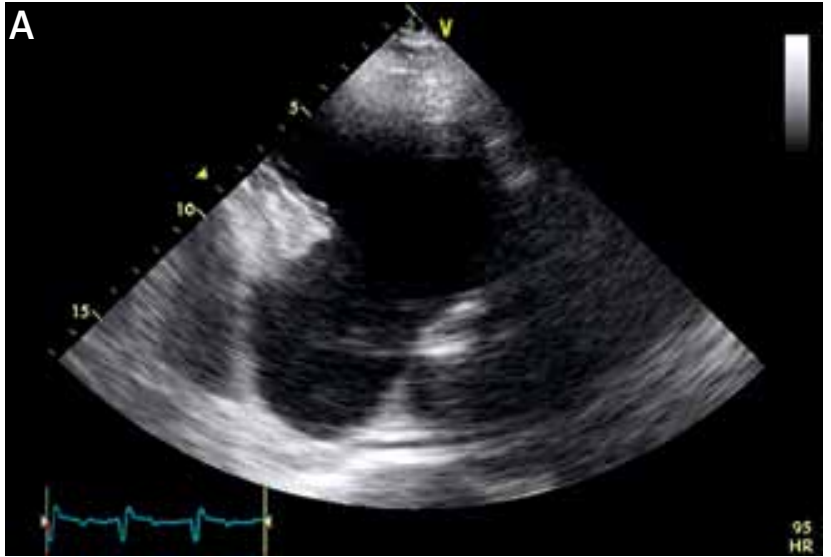

Fig. 1. Echocardiographic examination. A) Apical two-chamber view. B) Apical two-chamber view: the jet of a paravalvular leak directed into the false aneurysm cavity

a small paravalvular leak directed into the false aneurysm's lumen was visualized (Fig. 1B). Coronary angiography demonstrated an $80 \%$ constriction in the right coronary artery with its distal occlusion as well as diffuse lesions up to $40 \%$ in the circumflex artery and the marginal branch. Bypass angiography visualized the normal functioning of the Ao-RCA bypass with mural changes; the Ao-OM bypass or its stump were not visualized. Contrast-enhanced multislice computed tomography of the heart confirmed the presence of a large false aneurysm exiting the posterior and inferior wall; max. dimensions: $79.3 \mathrm{~mm} \times 75.3 \mathrm{~mm}$, entrance size: $51.8 \mathrm{~mm}$ (Fig. 2).

After consultation with a cardiac surgeon, the patient was qualified for surgical treatment. Under extracorporeal circulation, a large aneurysm was found on the inferior wall at the base of the heart; it was strongly attached to the
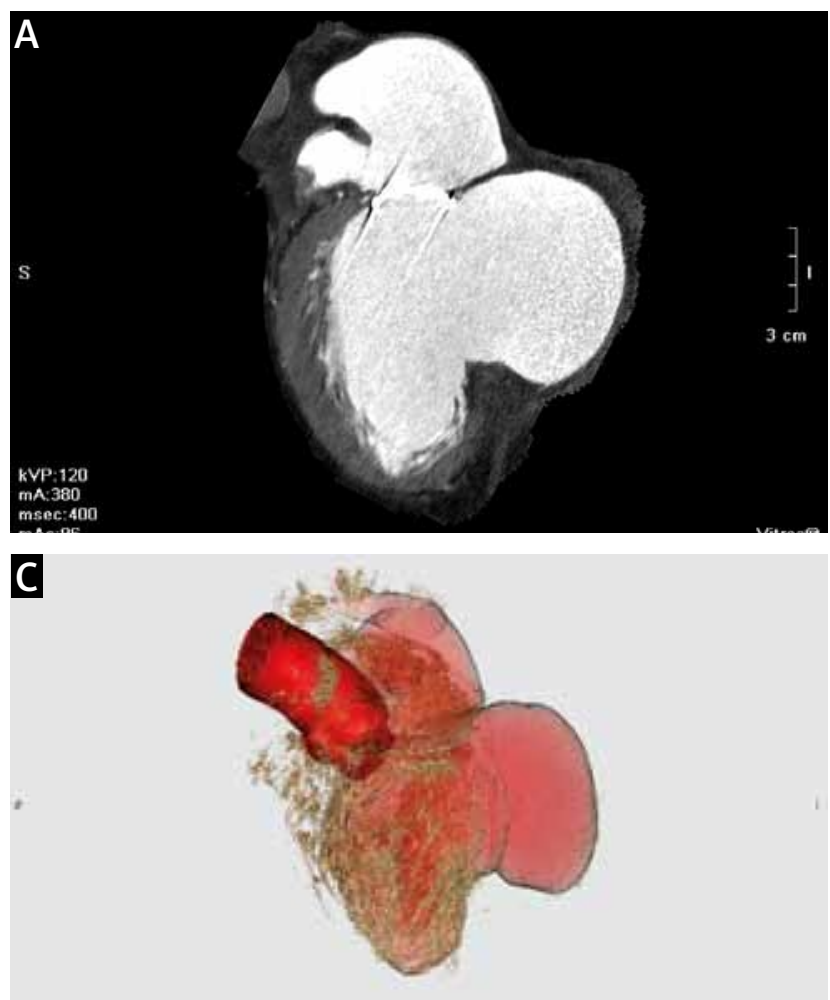

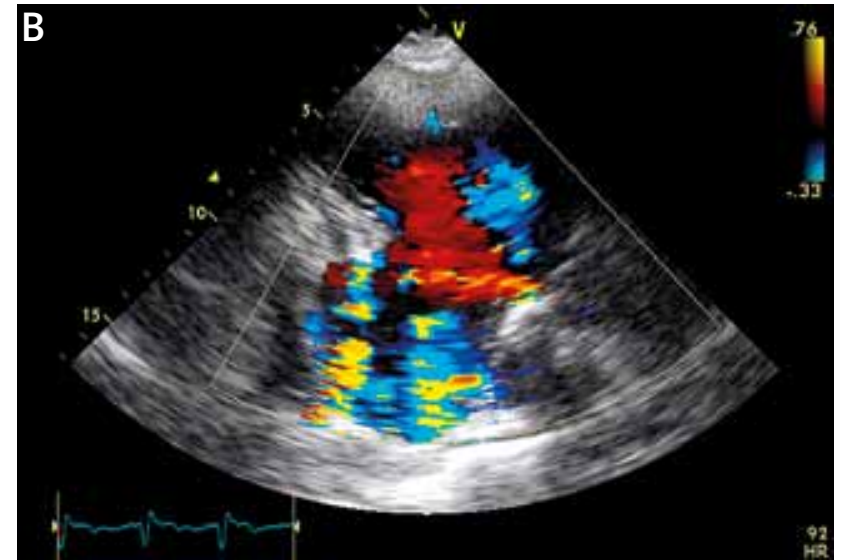

pericardial sac and perforated during attempts to dissect it. The aneurysm's entrance encompassed the area from the interventricular septum and the mitral annulus on one side to the origin of the anterolateral papillary muscle on the other, extending across approximately half of the inferior wall in the direction of the apex. A Dacron patch (approx. $5 \times 5 \mathrm{~cm}$ in size) was fixed on the side of the left ventricular lumen with single 2-0 polyester mattress sutures on Teflon pledgets and tied on Teflon strips on the side of the free wall, thus recreating the normal shape and dimensions of the left ventricular cavity. The remaining wall of the aneurysm was closed in an overlapping tile-like manner above the Dacron patch (Fig. 3).

Control echocardiography revealed: $4 \mathrm{C}$ - end-diastolic volume (EDV) $182 \mathrm{ml}$, end-systolic volume (ESV) $122 \mathrm{ml}$, left ventricular ejection fraction (LVEF) 33\%; 2C - EDV 165

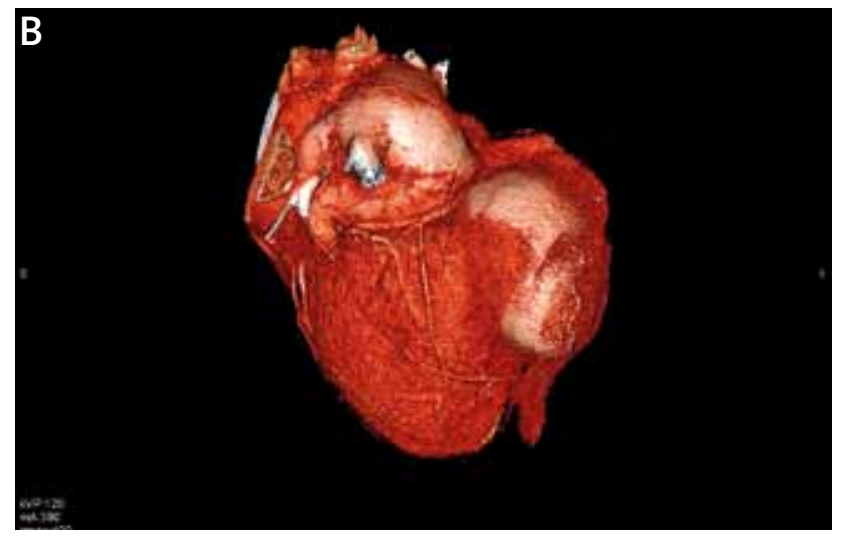

Fig. 2. Contrast-enhanced computed tomography of the heart before the cardiac procedure. A) Longitudinal section of the left ventricular wall and the sac of the false aneurysm. B) Three-dimensional reconstruction. C) Ventriculographic reconstruction ("glass heart" technique) 

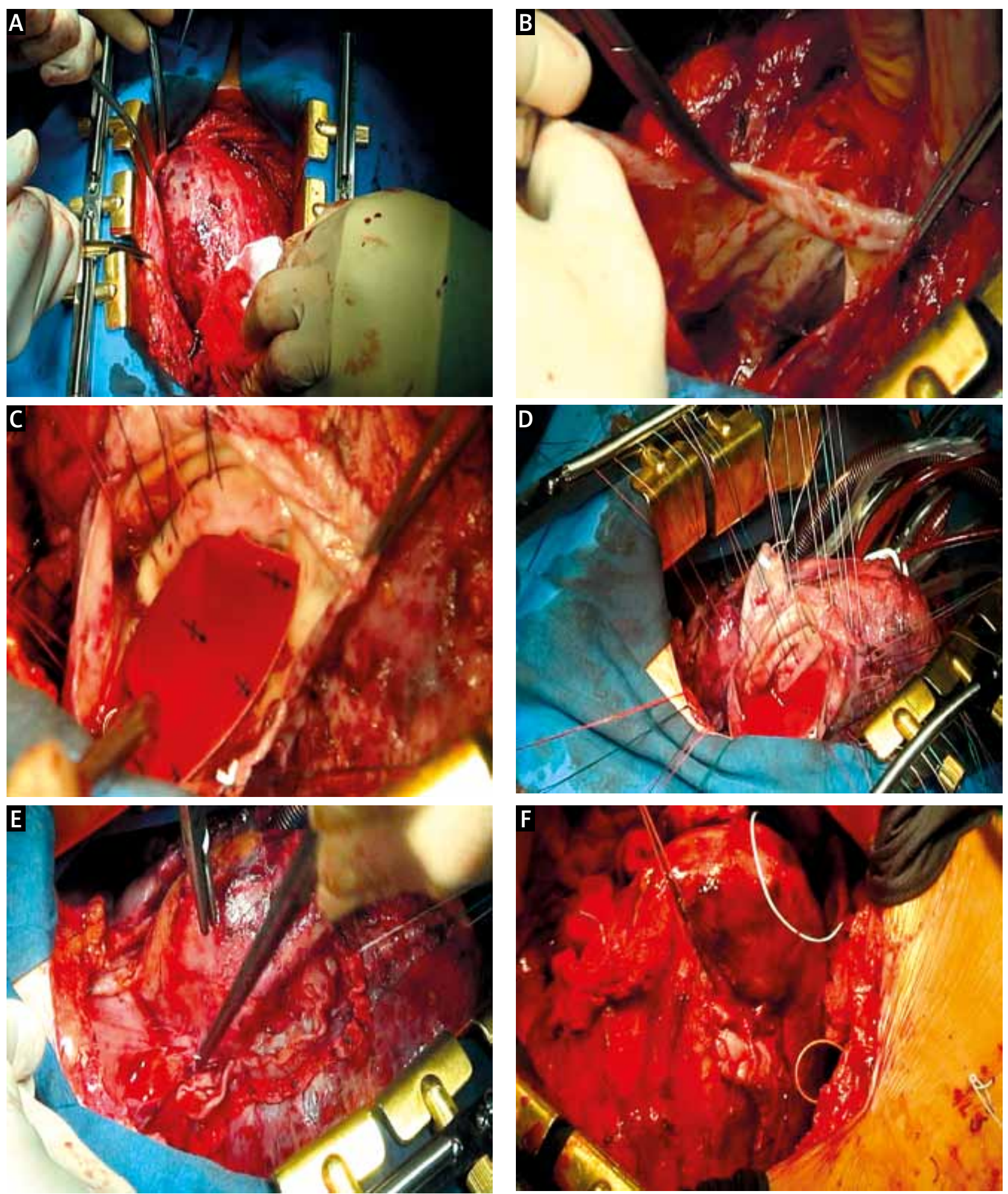

Fig. 3. Intraoperative photographs. A) The opened pericardial sac and the aneurysm, partially dissected from the parietal pericardium; bloody material effusing through the thinned wall. B) The interior of the left ventricle after the opening of the aneurysm, its thin wall, the mitral valve on the right side, and LVOT on the left. C) The partially sutured Dacron patch. D) The patch after completion of suturing. E) The ventricular wall is sutured over in layers with the aneurysm tissue; on the right side, a Teflon strip is visible, strengthening the area of the aneurysm entrance. $F$ ) The final result - control uncovering of the heart after restoration of circulation

ml, ESV 133 ml, LVEF 19\% (initially: 4C - EDV 184 ml, ESV 129 ml, LVEF 30\%; 2C - EDV 478 ml, ESV 455 ml, LVEF 5\%). No perioperative complications were noted. Three months af- ter the surgery, the patient was in functional NYHA class II. Control echocardiography and computed tomography (Fig. 4) confirmed a reduction of left ventricular dimen- 
sions, an improvement of left ventricular ejection fraction (35\%), and no signs of an aneurysm.

\section{Discussion}

A myocardial pseudoaneurysm (false aneurysm) is a complication that is rare and difficult to discover during a routine examination, but which can result in severe consequences. It develops as a result of myocardial free wall rupture, and its external boundary is constituted by the pericardium. Pseudoaneurysms, even if small and asymptomatic, tend to rapidly expand their dimensions, which increases the risk of their rupture and consequent life-threatening tamponade [1, 2]. Late myocardial rupture, as in the described case, occurs within days or years after the myocardial infarction or the cardiac surgery procedure and results in the development of a false aneurysm; if the lesion does not cause any symptoms, it may go unnoticed and therefore remain untreated [3].

The factors predisposing to the development of a left ventricular pseudoaneurysm include primarily: myocardial infarction, cardiac surgery procedures (especially mitral valve replacement and coronary bypass grafting), injuries, and infections [4]. False aneurysms are encountered in 4\% of patients who suffered an infarction and in $23 \%$ of patients who died as a result of it [5]. It is postulated that inferior wall infarctions are the most common risk factor for left ventricular pseudoaneurysm development, predisposing to this lesion twice more frequently than anterior wall infarctions [6]. False aneurysms are most often located on the anterior, inferior, or lateral wall or on the apex of the heart $[1,6]$, which stems from the protective action of the pericardial sac and the restricted possibility of aneurysm expansion in these locations. Due to the overlap of several factors, the described patient was burdened with a relatively high risk of pseudoaneurysm development.

The most frequently observed subjective symptoms, also typical of, e.g., coronary artery disease, include symptoms of congestive circulatory failure (36\%), anginal pain (30\%), and dyspnea (25\%); less commonly, ventricular arrhythmias may be encountered, as well as less specific symptoms: cough, vertigo, or impaired mental function [3, $6,7]$. Notwithstanding, it is estimated that over $10-12 \%$ of patients may remain asymptomatic $[1,6,7]$. The situation is similar as regards objective signs. Changes observed in chest X-ray (cardiac silhouette enlargement), ECG (persistent postinfarction ST-segment elevation, which can also occur in the case of a true left ventricular aneurysm [5]), and physical examinations (murmurs present in approximately $70 \%$ of patients [3]) are often nonspecific; however, in combination with detailed medical history and risk factor evaluation, they may suggest a preliminary diagnosis [6]. The symptoms may often erroneously suggest mitral insufficiency. In patients after mitral valve replacement, as was the case with our patient, the possibility of a dysfunction of the prosthetic valve or a paravalvular leak should also be taken into consideration [6]. The frequency of false aneurysm development after mitral valve replacement is
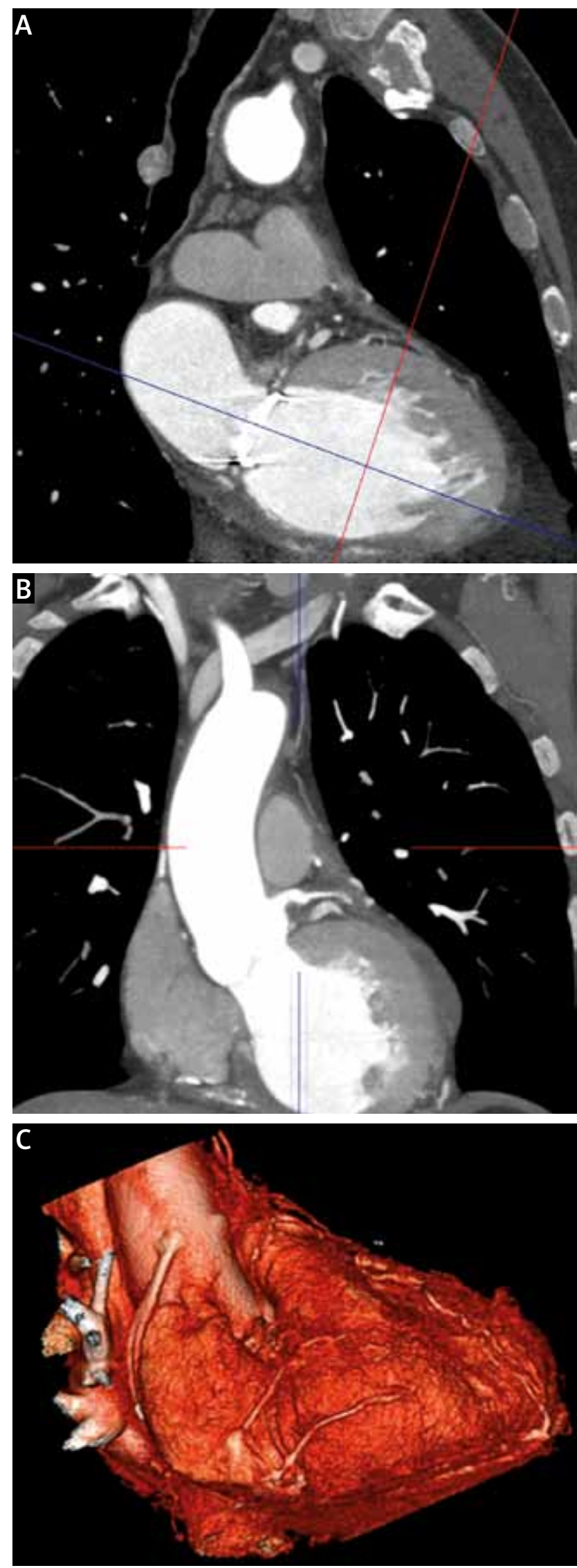

Fig. 4. Contrast-enhanced computed tomography of the heart after the cardiac procedure. A, B) Longitudinal section of the left ventricular wall. C) Three-dimensional reconstruction 
low, being estimated at between $0.02 \%$ and $2.0 \%$ [2]. In the case of the described patient, it is difficult to unequivocally pinpoint the moment at which the false aneurysm developed. The process was most likely initiated during the perioperative period; it is worth underscoring that the procedures of coronary artery bypass grafting and mitral valve replacement were performed in emergency mode during the acute phase of myocardial infarction.

Cases of embolism with thrombotic material originating from the lumen of the false aneurysm have been described $[1,3]$. Another factor predisposing the studied patient to embolism was paroxysmal atrial fibrillation. However, the patient received continuous anticoagulative treatment (on account of the prosthetic mitral valve), and no systemic embolism was observed. On the other hand, the paravalvular leak flowing in the direction of the aneurysm cavity restricted the possibility of thrombus formation.

In order to determine the further course of action, it is important to differentiate between true and false aneurysms - in the case of the former, the myocardium undergoes local dilatation, not rupture. False aneurysms are characterized by a relatively high risk of rupture; therefore, urgent surgical treatment is recommended. The operative risk in this case is lower than the risk associated with further conservative treatment [4-8]. The established methods of examination aimed at forming a diagnosis include transthoracic/transesophageal echocardiography, magnetic resonance tomography, ventriculography, computed tomography, and radioisotope imaging $[5,6$, 8]. Echocardiography is a useful form of preliminary examination, enabling the assessment of myocardial injury or dyskinesia as well as the maximal dimensions of the aneurysm's entrance and sac. The diagnosis of a false aneurysm may be indicated by myocardial rupture as well as by a clear boundary between the ventricular wall and the aneurysm wall, usually constituted by thickened pericardial plaques. A narrow aneurysm entrance followed by a large dilation of the aneurysm sac may also indicate this diagnosis [2]. However, echocardiography is not always able to distinguish between the two lesions, especially if they are chronic in nature. In the case of a true aneurysm, the myocardial layer may be very thin, but the differentiation may be further impeded in the presence of increased fibrosis. In the described case, the echocardiographic image suggested a rupture of the inferior wall, but the wide entrance was not typical of a false aneurysm. In order to obtain a precise view of the pathology and determine a treatment strategy, additional imaging techniques had to be used. Ultimately, computed tomography confirmed the preliminary diagnosis. It also proved useful in monitoring the long-term effects of the procedure.

From the surgical point of view, there are important differences in the methods of treating inferior wall an- eurysms and the more common apical or anterior wall aneurysms. In the case of anterior-apical lesions, Dor's technique with Menicanti's modification is used; it involves reducing the aneurysm entrance with purse-string sutures, while a Dacron patch, oblong and relatively small, serves to recreate the proper shape of the heart's left ventricle and prevents the left ventricular cavity from being too small [9]. In the case of very large aneurysms and significant left ventricular remodeling, it is possible to recreate the normal shape and size of the left ventricle without the use of the patch [10]. In the case of inferior wall aneurysms, the purse-string suture is not used, and the shape and size of the aneurysm entrance are not modified, but closed with a patch. Any attempt to suture an inferior wall aneurysm together without the use of a patch is doomed to failure due to the excessive tension of the wall and the proximity of the mitral annulus. Another issue is the influence of inferior wall aneurysm repair on mitral valve function. Due to the proximity of the valve apparatus, the proper selection of the size and shape of the patch may facilitate the abatement of ischemic mitral insufficiency. Nonetheless, it should be remembered that, for the same reasons, the operation may intensify mitral insufficiency. In the described case, the presence of the previously implanted mechanical mitral prosthesis, in a sense, facilitated the surgeon's task.

\section{Disclosure}

Authors report no conflict of interest.

\section{References}

1. Koçak H, Becit N, Ceviz M, Unlü Y. Left ventricular pseudoaneurysm after myocardial infarction. Heart Vessels 2003; 18: 160-162.

2. Eren E, Bozbuga N, Toker ME, Keles C, Rabus MB, Yildirim O, Guler M, Balkanay M, Isik O, Yakut C. Surgical treatment of post-infarction left ventricular pseudoaneurysm: a two-decade experience. Tex Heart Inst J 2007; 34: 47-51.

3. Komeda M, David TE. Surgical treatment of postinfarction false aneurysm of the left ventricle. J Thorac Cardiovasc Surg 1993; 106: 1189-1191.

4. Raghav KP, Makkuni P, Figueredo VM. A review of electrocardiography in pulmonary embolism: recognizing pulmonary embolus masquerading as ST-elevation myocardial infarction. Rev Cardiovasc Med 2011; 12: 157-163.

5. Zoffoli G, Mangino D, Venturini A, Terrini A, Asta A, Zanchettin C, Polesel E. Diagnosing left ventricular aneurysm from pseudo-aneurysm: a case report and a review in literature. J Cardiothorac Surg 2009; 4: 11.

6. Frances C, Romero A, Grady D. Left ventricular pseudoaneurysm. J Am Coll Cardiol 1998; 32: 557-561.

7. Makkuni P, Kotler MN, Figueredo VM. Diverticular and aneurismal structures of the left ventricle in adults: report of a case within the context of a literature review. Tex Heart Inst J 2010; 37: 699-705.

8. Dubey L, Timala R, Adhikari R, Sharma S, Gautam M, Gautam S. Unruptured left ventricular pseudoaneurysm following inferior wall myocardial infarction. Cardiol J 2012; 19: 539-542.

9. Menicanti L, Di Donato M. The Dor procedure: what has changed after fifteen years of clinical practice? J Thorac Cardiovasc Surg 2002; 124: 886-890.

10. Deja MA, Malinowski M, Biernat J, Wos S. Left ventricular aneurysm that grew to rupture. Interact Cardiovasc Thorac Surg 2010; 11: 196-198. 